\title{
Effect of air parameters, water temperature, and number of pool occupants on moisture gains
}

\author{
Agnieszka Garnysz-Rachtan ${ }^{1, *}$, and Zbigniew Zapałowicz ${ }^{1}$ \\ ${ }^{1}$ West Pomeranian University of Technology, Szczecin; Department of Heat Engineering, al. Piastów 17, PL-70-310 Szczecin, Poland
}

\begin{abstract}
Thermal calculations for indoor swimming pools require that amount of water evaporated from the pool's water surface, as well as water evaporated from the floor surrounding the pool and from the bodies of the occupants are to be determined. It means in practice that amount of vapor transferred to the air in the pool hall depends most of all on physical parameters of water and air. One of more important factors that affect water evaporation is also the way the pool is operated. The present article shows only chosen relations applied to determine the values of evaporation rate from occupied pool. The relations also account for the mode of pool's operation. The aim of the paper is to analyse the effect of changes of temperature and of relative air humidity in the hall, of water temperature and of air velocity above the water surface, as well as of the number of occupants on moisture gains in the hall. The above data let choose the right relation to be applied in calculations for the water evaporation rate.
\end{abstract}

\section{Introduction}

One of the steps in constructing ventilation systems or air-conditioning systems for a pool hall is determination of the amount of evaporated water in the object $[1,2]$. The literature gives a number of relations that allow to determine the evaporation rate for indoor swimming pools [1-8]. This paper presents only methodologies to determine moisture gains in occupied pools. Persons present in the pool hall cause increase of evaporation intensity in comparison with the same parameters at evaporation from a calm water surface. The additional gains are caused by increase of water surface as a result of its roughness by water evaporation from the floor around the pool, and by wet bodies of occupants, as well as by emission of vapor during their breathing. Authors of so far proposed relations to determine the evaporation rate account differently for the additional moisture gains. The case will be discussed further in the paper (section 2).

Indoor swimming pools can be divided according to the operation mode as $[2,9]$ : residential pools (private), recreational pools (of general purpose), school pools, competition pools, and therapeutic pools. These objects are characterized with various requirements concerning water temperature, temperature and relative humidity of air in the hall, as well as air velocity over the water surface $[2,8,9]$. Table 1 , elaborated on the basis of $[2,9]$, shows the most frequent ranges of changes for these parameters. A number of authors advise to assume the air temperature in the hall to be by $2 \div 4 \mathrm{~K}$ higher than the water temperature. Air temperatures ranges in the hall given in Table 1 are determined by assumption that the air temperature is by $2 \mathrm{~K}$ higher than water temperature. The tally of parameters neglects the ones that are valid for residential and therapeutic pools. Besides, the last column in Table 1 presents water surface area required per each occupant.

The aim of the paper is to analyse the effect of changes of temperature and relative air humidity in the hall, water temperature and air velocity above the water surface, as well as the number of occupants on moisture gains in the hall. The above data let choose the right relation to be applied in calculations for the water evaporation rate.

Table 1. Required parameters of water and air for chosen types of swimming pools [2, 9].

\begin{tabular}{|c|c|c|c|c|c|}
\hline \multirow{2}{*}{ pool type } & $\begin{array}{c}\text { water } \\
\text { temperature }\end{array}$ & $\begin{array}{c}\text { air } \\
\text { temperature }\end{array}$ & $\begin{array}{c}\text { air } \\
\text { humidity }\end{array}$ & $\begin{array}{c}\text { air } \\
\text { velocity }\end{array}$ & $\begin{array}{c}\text { water surface area per } \\
\text { occupant }\end{array}$ \\
\cline { 2 - 3 } & ${ }^{\circ} \mathrm{C}$ & ${ }^{\circ} \mathrm{C}$ & $\%$ & $\mathrm{~m} / \mathrm{s}$ & $\mathrm{m}^{2} /$ person \\
\hline recreational & $24 \div 32$ & $26 \div 34$ & & & $3 \div 3,5$ \\
\hline school & $26 \div 30$ & $28 \div 32$ & \multirow{2}{*}{$40 \div 70$} & $0,05 \div 0,3$ & $5 \div 6$ \\
\hline competition & $22 \div 28$ & $24 \div 30$ & & & $8 \div 10$ \\
\hline
\end{tabular}

\footnotetext{
Corresponding author: agnieszka.garnysz@zut.edu.pl
} 


\section{Relations that determine evaporation rate in pools with occupants}

The literature gives a number of relations that allow to determine the evaporation rate for indoor swimming pools. The present article is confined only to presentation of the relations which relate to occupied pools $[1,6,10-15]$. Chosen relations used to determine evaporation rate in pools during their operation are presented in Table 2.

According to Dalton's law, the amount of evaporated water is proportional to difference of vapor partial pressures in the thin layer of air direct above the water surface (in the boundary layer) and in the air around the pool $(\Delta p)$, as well as to evaporation coefficient $(\varepsilon)$ :

$$
E=\varepsilon \cdot \Delta p
$$

Having regard to the relation between vapor partial pressure and content of humidity in the air, difference of partial pressures $\Delta p$ present in equation (1a) can be replaced by the difference of humidity content $\Delta x$, then equation (1a) has the form:

$$
E=\sigma \cdot \Delta x
$$

Common feature of relations given in Table 2 and applied to calculate the evaporation rate is that coefficients $\varepsilon, \sigma$ are composite functions. Therefore, some of researchers propose only modifications of relations that apply for calm water surface, in order to take into consideration the effect of additional moisture gains caused by presence of occupants.

Labohm [1], in equation (7), took into account the evaporation coefficient which could be calculated from Sprenger relation $(\sigma=25+19 \cdot w)$. According to this author, the value of evaporation rate obtained by means of Sprenger formula should be increased by $200-250 \%$, by application of correction factor $K_{L}=3 \div 3,5$. Then, correction factor takes into account the additional water evaporation from the wet surface of occupants' bodies, from wet floors, and as a result of rough water in the pool. Kappler [12] refers also to Sprenger relation. However, in order to take into account additional gains of vapor emitted by occupants, and as a result of evaporating of the water film wetting their bodies, he gives different values of correction factor in equation (6) - coefficient $K_{K}$. According to Besler [10], the following factors should be related in calculations concerning occupied pool: temperature rise on water surface, evaporation from the wet surfaces of occupants' bodies, and significant increase of water surface through its turbulence. It results from Besler's considerations that the relation of Ferencowicz [10], applied to determine evaporation rate from calm water, can be used for calculations, however on condition that this parameter will be increased by $180 \%$ - equation (3).

\begin{tabular}{|c|c|c|c|}
\hline researcher, source & relation & remarks & $\begin{array}{c}\text { number of } \\
\text { equation }\end{array}$ \\
\hline ASHRAE, [14] & $E=F_{A} \cdot\left[3,6 \cdot \frac{(0,089+0,0782 \cdot w) \cdot \Delta p}{Y}\right]$ & $\begin{array}{l}F_{A}=0,5 \text { residential pools } \\
F_{A}=0,65 \text { condominium and therapeutic } \\
\quad \text { pools } \\
F_{A}=0,8 \text { hotel pools } \\
F_{A}=1,0 \text { public, school, competition pools }\end{array}$ & (2) \\
\hline Besler, [10] & $E=2,8 \cdot\left(A_{F}+17,4 \cdot w\right) \cdot 10^{-3} \cdot \frac{760}{p_{b}} \cdot \Delta p$ & $\begin{array}{l}A_{F}=23 \text { for } t_{w}<30^{\circ} \mathrm{C} \\
A_{F}=28 \text { for } 30^{\circ} \mathrm{C}<t_{w}<40^{\circ} \mathrm{C}\end{array}$ & (3) \\
\hline $\begin{array}{l}\text { Biasin\&Krumme, } \\
{[11]}\end{array}$ & $E=\left[0,118+0,01995 \cdot \frac{\Delta p}{133,3} \cdot \varepsilon_{B K}\right]$ & $\varepsilon_{B K}=\frac{N}{A \cdot 0,167} \approx 6 \cdot N^{*} ; \varepsilon_{B K} \leq 0,75$ & (4) \\
\hline Hens, [6] & $E=0,0000409 \cdot\left(1+8,46 N^{*}\right) \cdot \Delta p$ & & $(5)$ \\
\hline Kappler, [12] & $E=K_{K} \cdot(25+19 \cdot w) \cdot \Delta x$ & $\begin{array}{ll}K_{K}=1,1 & \text { private indoor pools } \\
K_{K}=1,1 \div 1,15 & \begin{array}{l}\text { general purpose pools } \\
\text { (recreational pools) }\end{array} \\
K_{K}=1,2 & \text { hotel and school pools }\end{array}$ & (6) \\
\hline Labohm, [1] & $E=K_{L} \cdot(25+19 \cdot w) \cdot \Delta x$ & $K_{L}=3 \div 3,5$ & (7) \\
\hline Shah, [6] & $\begin{array}{l}E=\left(1,9-21\left(\rho_{a}-\rho^{\prime \prime}{ }_{w g}\right)+5,3 N^{*}\right) \cdot E_{o} \\
\text { where: } E_{o}=\max \left\{\begin{array}{c}35 \rho^{\prime \prime}{ }_{w g}\left(\rho_{a}-\rho^{\prime \prime}{ }_{w g}\right)^{1 / 3} \cdot \Delta x \\
0,00005 \cdot \Delta p\end{array}\right.\end{array}$ & $\begin{array}{l}\text { Equation is applicable to } \mathrm{N}^{*} \geq 0,05 ; \\
\text { For } N^{*}<0,05 \rightarrow \text { to perform linear } \\
\text { interpolation between } E / E_{o} \text { at } N^{*}=0,05 \\
\text { and } E / E_{o}=1 \text { at } N^{*}=0 \text {. } \\
\text { For }\left(\rho_{a}-\rho^{\prime \prime}{ }_{w g}\right)<0, \text { use }\left(\rho_{a}-\rho^{\prime \prime}{ }_{w g}\right)=0\end{array}$ & $(8)$ \\
\hline Smith et al., [15] & $E=1,26 \cdot\left[3,6 \cdot \frac{(0,089+0,0782 \cdot w) \cdot \Delta p}{Y}\right]$ & & (9) \\
\hline $\begin{array}{l}\text { VDI/Recknagel, } \\
{[13]}\end{array}$ & $E=\frac{\beta_{b}}{461,52 \cdot\left[0,5 \cdot\left(t_{w}+t_{a}\right)+273,15\right]} \cdot \Delta p$ & $\begin{array}{ll}\beta_{\mathrm{b}}=21 & \text { private pool } \\
\beta_{\mathrm{b}}=28 & \text { swimming/recreational pool; with } \\
& \text { depth less than } 1,35 \mathrm{~m} \\
\beta_{\mathrm{b}}=40 & \text { swimming/recreational pool; with } \\
& \text { depth more than } 1,35 \mathrm{~m} \\
\beta_{\mathrm{b}}=50 & \text { wave pool during work }\end{array}$ & $(10)$ \\
\hline
\end{tabular}

Table 2. Relations applied to calculate evaporation rates in occupied swimming pools. 
Smith, Löf and Jones [15] carried out experimental research for indoors and outdoors pools, both for calm water surface, and during the activity of occupants. The quantity of evaporating water from indoor pool was estimated on the basis of energy balance for water in the pool, by means of water temperature measurements results. The authors compared the obtained experimental data with calculation results obtained from Carrier equation recommended at that time in the ASHRAE handbook. They came to the conclusion that evaporation rate determined from Carrier equation should be increased by $26 \%$. Smith, Löf and Jones proposed equation (9) for calculations. In the meantime, as it was given in [14], experimental research showed that evaporation rate determined from Carrier equation had too high value. The problem was noticed also by ASHARE which introduced coefficient $F_{A}$, called activity coefficient, in equation (2) in 2007. Values of $F_{A}$ were not determined on the basis of experimental research, but they were stated arbitrarily on the meeting of members of ASHRAE [14].

The next group of relations applied for calculations of moisture gains are equations that require determination of occupants' number. Hens [6] presented relation (5), obtained on the basis of measurement results carried out at university pool where one of parameters was the number of occupants per pool surface area (parameter $N^{*}$ ). Biasin \& Krumme [11] determined the quantity of evaporating humidity in a real object, on the basis of the quantity of condensate collected by the air conditioning system operating in the pool hall, changing rooms, and shower rooms. On the basis of additional measurements concerning the operation of showers, Biasin \& Krumme came to the conclusion that moisture present in shower rooms does not affect meaningfully the water evaporation rate. According to the carried out regression analysis of measurement data, they proposed the relation (4). Shah proposed relation (8) in [6]. He elaborated the relation on the basis of measurement data analysis in experimental research for occupied indoor pools, however, he obtained the data from publications of other authors. Shah took into regard the effect of occupants' number and of difference of air density in the hall and over the evaporation surface. Evaporation rate $E_{o}$, present in equation (8) concerns evaporation from unoccupied pool and is discussed by Shah in [14].

The newest issue of Recknagel et al. [13] presents relation (10), given in updated guidelines of Association of German Engineers VDI 2089-1:2006-2009. According to [16], equation (10) is a formula resulting from the equation of mass conservation and value of mass transfer coefficient $\beta_{b}$ was determined by recalculation of water evaporation coefficients present in the former version of VDI 2089 guidelines. Given values of mass transfer coefficient $\beta_{b}$ take into account evaporation from overflow gutter, wet clothes and surfaces of occupants' bodies, and water vapor included in the air breathed out by occupants.

\section{Research results and discussion}

\subsection{Basic assumptions}

Relations given in Table 2 were applied to calculate the rate of evaporation of water.

In order to determine parameters of boundary layer, it is necessary to know the temperature of this layer. One of ways to determine the boundary layer temperature is to assume for calculations the temperature of water surface. It can be determined from the relation $[1,2]$ :

$$
t_{W S}=t_{w}-0,125 \cdot\left(t_{w}-t_{W B}\right)
$$

Papers $[1,2]$ point out that temperature of boundary layer is assumed as equal with water temperature in order to simplify calculations, and respective corrections caused by the above assumption are taken into regard by correction factors. A principle has been adopted in the present paper, that if the reference does not point out clearly that water temperature should be applied for calculations, then water surface temperature is used. On the above basis, water temperature was applied in calculations for equations (3), (4), (6), (9), (10), and water surface temperature calculated from equation (11) was applied in equations (2), (5), (7), (8)

Among relations presented in Table 2, three of them require previous determination of values of correction factors with regard to the kind of pool under consideration. In case of relation proposed by ASHRAE (2), pools analysed in the paper can be regarded as the ones for which activity factor $F_{A}$ equals 1,0. Kappler formula (6) does not take into regard the correction factors for competition pools, and it distinguishes various values of correction factor for school and public pools. Because of the above fact, mean value of correction factor $\left(K_{K}=1,18\right)$ was assumed for calculations for school and public pools. In formula proposed by VDI/Recknagel (10), two variants of correction factors were assumed for public and recreational pools, depending on the depth of the pool. There is a lack of data concerning the correction factors for competition pools. The present paper presents calculations for two values of this factor, that is $\beta_{b}=28$, and $\beta_{b}=40$. In case when formula of Labohm (7) is used, it is unknown for which types of pools the values of correction factor are given. Labohm has only given the changes range for this factor. Therefore, mean value of correction factor, $K_{L}=3,3$, was assumed for the calculations. In turn, formulas given by Biasin \& Krumme (4), Hens (5), and Shah (8) require the number of occupants per pool surface area (parameter $N^{*}$ ). Thus, on the basis of required area of water surface per one occupant (Table 1), mean occupants' number per $1 \mathrm{~m}^{2}$ of surface was determined for chosen type of pool. Values of parameter $N^{*}$ equalled respectively: 0,31 occupants $/ \mathrm{m}^{2}$ for recreational (public) pools, 0,18 occupants $/ \mathrm{m}^{2}$ for school pools, and 0,11 occupants $/ \mathrm{m}^{2}$ for competition pools. 


\subsection{Moisture gains calculation in swimming pool hall}

It was assumed for calculations that water temperature in the pool equalled $27^{\circ} \mathrm{C}$, and temperature and relative humidity of the air in the hall equalled $29^{\circ} \mathrm{C}$ and $55 \%$, respectively (mean values of particular parameters, according to Table 1). Requirements of thermal comfort for occupants state that air velocity over the water surface should not exceed $0,15 \mathrm{~m} / \mathrm{s}[4,14,17]$, so the above value was assumed for calculations. The number of occupants per pool's surface area (parameter $N^{*}$ ) was determined with regard to limitations of application of the Biasin \& Krumme formula (4), that is $\varepsilon_{\mathrm{BK}} \leq 0,75$. Limit value of coefficient $\varepsilon_{\mathrm{BK}}$ appeared when the number of occupants per $1 \mathrm{~m}^{2}$ of water surface equalled about 0,13 . Besides, it was assumed that atmospheric pressure equalled 1013,25 hPa.

Calculations results for evaporation rate obtained from analysed relations are presented in Fig. 1.

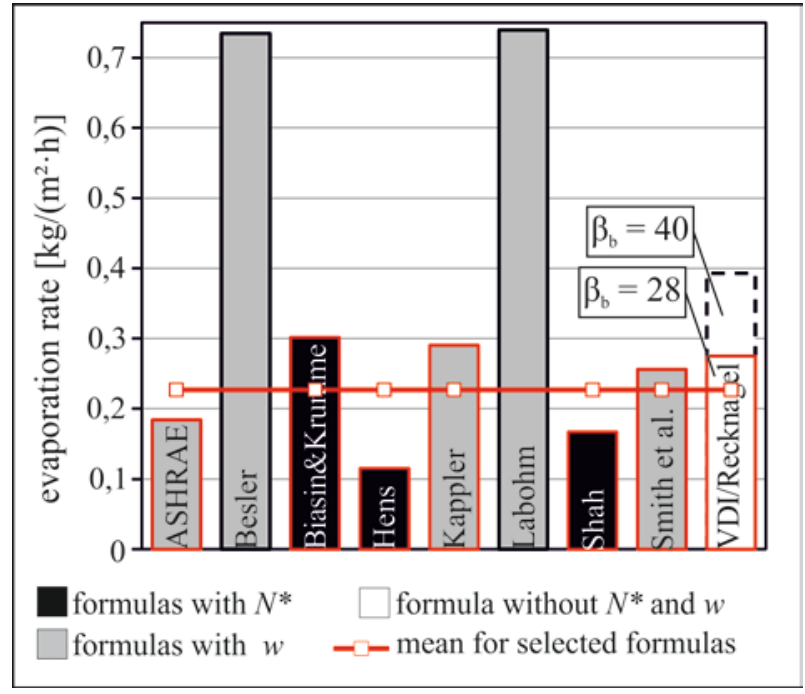

Fig. 1. Comparison of evaporation rate calculated by means of relations given in Table $2\left(N^{*}=0,13\right.$ occupants $/ \mathrm{m}^{2} ; t_{w}=27^{\circ} \mathrm{C}$; $\left.t_{a}=29^{\circ} \mathrm{C} ; \varphi=55 \% ; w=0,15 \mathrm{~m} / \mathrm{s}\right)$.

Values of evaporation rate calculated on the basis of equations proposed by Besler (3) and Labohm (7) are distinctly higher than the ones determined by means of the remaining relations (in the extreme case the difference equalled 543\%). For this reason, these relations were neglected in further analysis. After they were rejected from the analysis, difference of values of obtained results reached $162 \%$.

In case of relation advised by VDI/Recknagel (10), assumption of higher value of coefficient $\beta_{b}=40$ caused that calculated value of evaporation rate was by $43 \%$ higher than the one calculated for the lower value of the coefficient $\beta_{b}=28$. Thus, value of evaporation rate calculated for the lower value of $\beta_{b}$ is closer to the results obtained by means of remaining relations. Therefore, for further analysis, $\beta_{b}=28$ was assumed in relation (10) advised by VDI/Recknagel.

Fig. 1. shows also the mean value of evaporation rates calculated for the parameter in question, obtained after application of equations proposed by ASHRAE (2),
Biasin \& Krumme (4), Hens (5), Kappler (6), Shah (8), Smith et al. (9), and VDI/Recknagel (10) - when $\beta_{b}=28$. On the basis of the above, it was stated that values obtained from equations of Smith et al. (9), VDI/Recknagel (10), ASHRAE (2) were at closest to the mean value of evaporation rate. Whereas similar values of absolute differences in comparison with the mean value of evaporation rate were obtained by means of equations of Kappler (6), and Shah (8). The difference was positive when equation of Kappler (6) was applied and negative when equation of Shah (8) was applied. The biggest discrepancies among calculations for evaporation rate appeared when equation of Hens (5) was applied.

\subsection{Effect of conditions in swimming pool hall on moisture gains}

Conditions that are present inside the object affect relevantly the evaporation rate. This section of the paper presents results of research on effect of changes of air temperature and relative humidity of the air in the hall, of water temperature, and of air velocity over the water surface on evaporation rate. Ranges of changes of the above parameters given in Table 2 were assumed for calculations. Whereas in case of analysis concerning effect of the number of occupants on moisture gains, the range of changes of parameter $N^{*}=0,05 \div 0,33$ was assumed. The lower value of the above range is the limit value of application of the relation of Shah (8), and the upper value results from the minimal water surface area per one occupant (Table 1). The remaining parameters are compatible with assumptions made in sections 3.1 and 3.2 .

Effect of temperature and relative air humidity in the swimming pool hall

Values of evaporation rate in function of temperature and relative air humidity in the hall, calculated from relations given in Table 2, are presented in Fig. 2. Additionally, the chart shows runs of value changes of evaporation rate for three values of parameter $\mathrm{N}^{*}$ characteristic for three types of pools.

On the basis of analysis of calculations results given in Fig.2a, it can be observed that evaporation rate in the object rises with increase of air temperature in the hall, at simultaneous rise of water temperature (that is when relation $t_{w}=t_{a}-2$ is kept). In turn, rise of relative air humidity in the hall (Fig. 2b) decreases the rate of evaporation water.

Intensity of changes of evaporation rate with the change of temperature (Fig. 2a) and of relative air humidity (Fig. 2b) is for most of relations nearly the same. For example, decrease of relative air humidity from $70 \%$ to times $40 \%$ causes increase of evaporation rate by about 2,5 times. Only evaporation rate calculated from Biasin \& Krumme relation (4) changes to a smaller degree.

In case of equations where the number of occupants is not required, that is, when calculations are carried out 


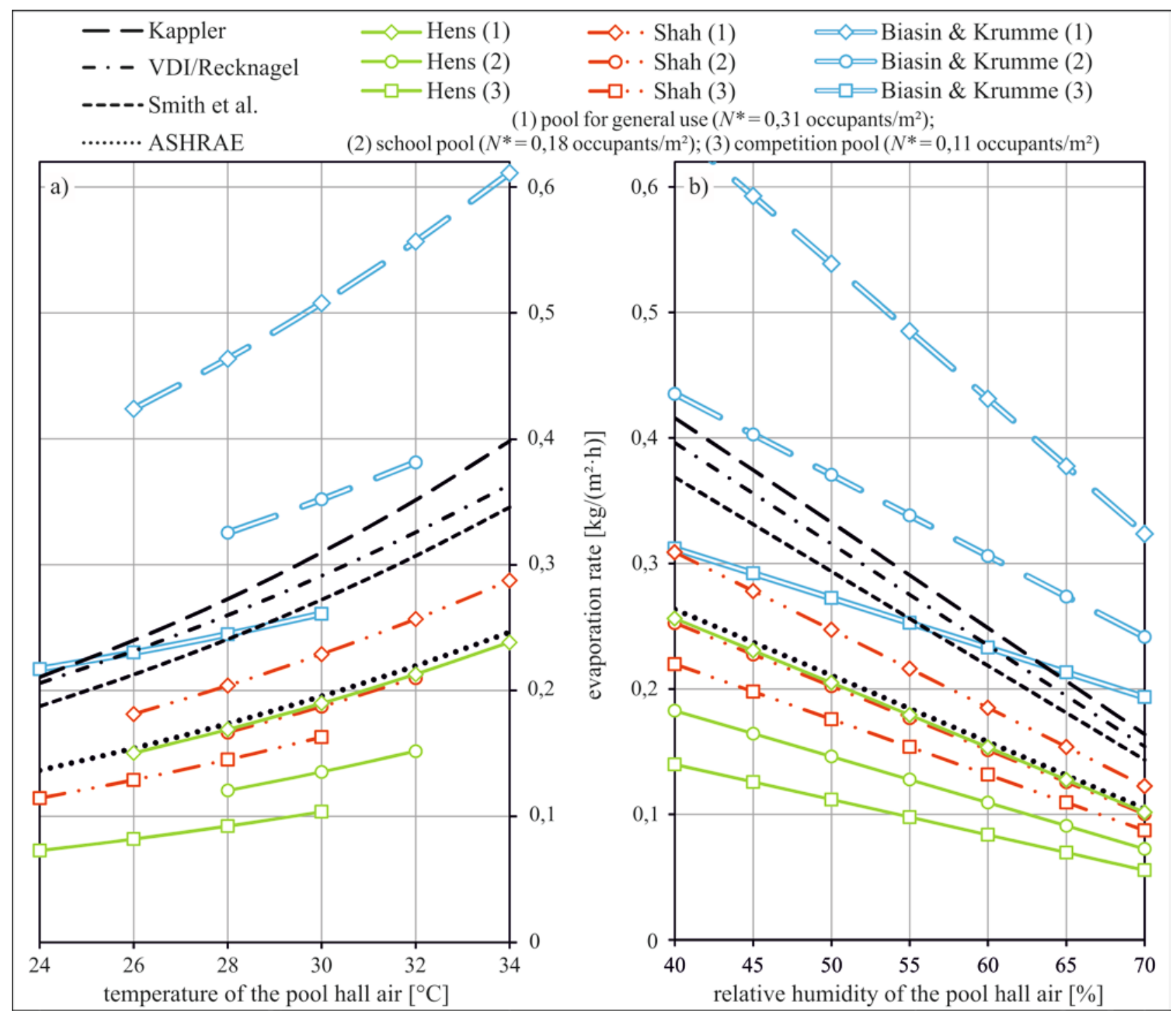

Fig. 2. Evaporation rate in function of: a) air temperature in the swimming pool hall $\left(t_{w}=t_{a}-2 ; \varphi=55 \%, w=0,15 \mathrm{~m} / \mathrm{s}\right)$; b) relative air humidity in the swimming pool hall $\left(t_{a}=29^{\circ} \mathrm{C}, t_{w}=27 ; w=0,15 \mathrm{~m} / \mathrm{s}\right)$.

by means of equations of Kappler (6), VDI/Recknagel (10), and Smith et al. (9), evaporation rate values are similar. Differences among values of this parameter equal from $12 \%$ to $14 \%$, depending on temperature and relative air humidity in the hall. Evaporation rate runs are also similar. If effect of air temperature in the hall (Fig. 2a) is analysed, then it is stated that by lower temperatures evaporation rate values obtained from equation VDI/Recknagel (10) are closer to the ones obtained from Kappler equation (6), and at higher air temperature, evaporation rate values are closer to the ones obtained from the equation of Smith et al. (9). On the other hand, when relative air humidity (Fig. 2b) changes, runs illustrating the changes of evaporation rate have the same character. Distinctly lower values of evaporation rate are obtained from equation of ASHRAE (2) in comparison to values calculated by means of equations of Kappler (6), VDI/Recknagel (10), and Smith et al. (9). For each of considered pool types, the lowest evaporation rate values are obtained by means of Hens relation (5). In turn, evaporation rates obtained from the Shah equation (8) are close to values calculated from equation of ASHRAE (2). In case of a pool with the highest number of occupants (public pool), values of evaporation rate are higher. They are at lower for the pool with lower occupants density (competition pool) and they are nearly equal for a school pool.

For school pools and recreational pools, evaporation rates, calculated by means of Biasin \& Krumme (4) relation, are distinctly higher than the one obtained by means of remaining equations. However, it should be kept on mind that the results are obtained for the coefficient $\varepsilon_{\mathrm{BK}}>0,75$.

\section{Effect of the water temperature in the pool}

Fig. 2 presents calculation results for evaporation rate against change of air temperature in the hall, by assumption that relation $t_{w}=t_{a}-2$ is valid. So, it can be concluded that analysis concerning effect of water temperature on evaporation rate is analogical as in the case of effect of air temperature in the hall on the evaporation rate. 


\section{Effect of air velocity over the water surface}

Calculation results of the evaporation rate calculated from relations presented in Table 2, for selected values of air velocity over water surface are presented in Fig. 3.

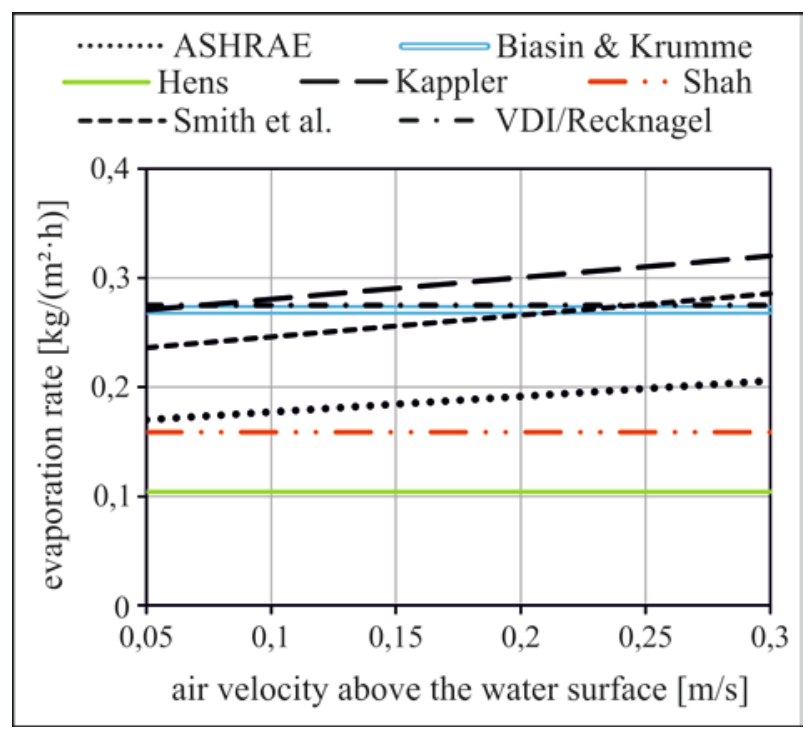

Fig. 3. Evaporation rate in the function of air velocity over the water surface $\left(N^{*}=0,13\right.$ occupants $/ \mathrm{m}^{2} ; t_{w}=27^{\circ} \mathrm{C} ; t_{a}=29^{\circ} \mathrm{C}$; $\varphi=55 \%)$.

The maximum values of the evaporation rate are obtained by application of relation of Kappler (6), whereas the minimum values are obtained by application of Hens (5). Differences in obtained results of evaporation rate equal from $165 \%$ (for $w=0,05 \mathrm{~m} / \mathrm{s}$ ) to $214 \%$ (for $w=0,3 \mathrm{~m} / \mathrm{s}$ ).

Only three formulas given in Table 2 take into regard the variation of moisture gains depending on the change of air velocity - relations: ASHRAE (2), Kappler (6), and Smith et al. (9). For these relations, rise of air velocity from the value of $w=0,05 \mathrm{~m} / \mathrm{s}$ to the value of $w=0,3 \mathrm{~m} / \mathrm{s}$, that is by $500 \%$ results only in $20 \%$ rise of evaporation rate. It can be then concluded that air velocity change over the water surface does not essentially affect the evaporation rate. Discrepancies in evaporation rate result most of all from the choice of particular relation, and not directly from the assumed value of air velocity.

\section{Effect of occupants' number}

Results of calculations for evaporation rate in the function of the number of occupants per $1 \mathrm{~m}^{2}$ of water surface are presented in Fig. 4. The chart presents also the mean value of evaporation rate calculated only on the basis of the relations where the number of occupants was not taken into regard (relations: ASHRAE (2), Kappler (6), Smith et al. (9), and VDI/Recknagel (10)) - mean 4 .

Values of evaporation rate calculated from equations advised by Kappler (6), Smith et al. (9), and VDI/Recknagel (10) are higher than the mean 4 . On the other hand, evaporation rate determined from equation of ASHRAE (2) is lower than the mean 4 .

Relation proposed by Biasin \& Krumme (4) takes into regard the number of occupants and is valid when the values of parameter $N^{*}$ are lower than 0,13 occupants $/ \mathrm{m}^{2}$. Additionally, Biasin \& Krumme state that no significant increase of evaporation rate is observed above this value, which means that evaporation rate remains unchanged despite the rise of occupants' number - see run B1 in Fig. 4. However, as it is presented in a number of publications, this limitation is rejected and thus the calculated evaporation rates can be overestimated for the values of $N^{*}>0,13$ occupants $/ \mathrm{m}^{2}$. In this case, changes of evaporation rate run are illustrated by the run B2 in Fig. 4. Values of evaporation rate obtained by means of equation of Biasin \& Krumme (4), with a small number of occupants $\left(0,05 \div 0,1\right.$ occupants $\left./ \mathrm{m}^{2}\right)$ are lower than the mean $\varangle$.

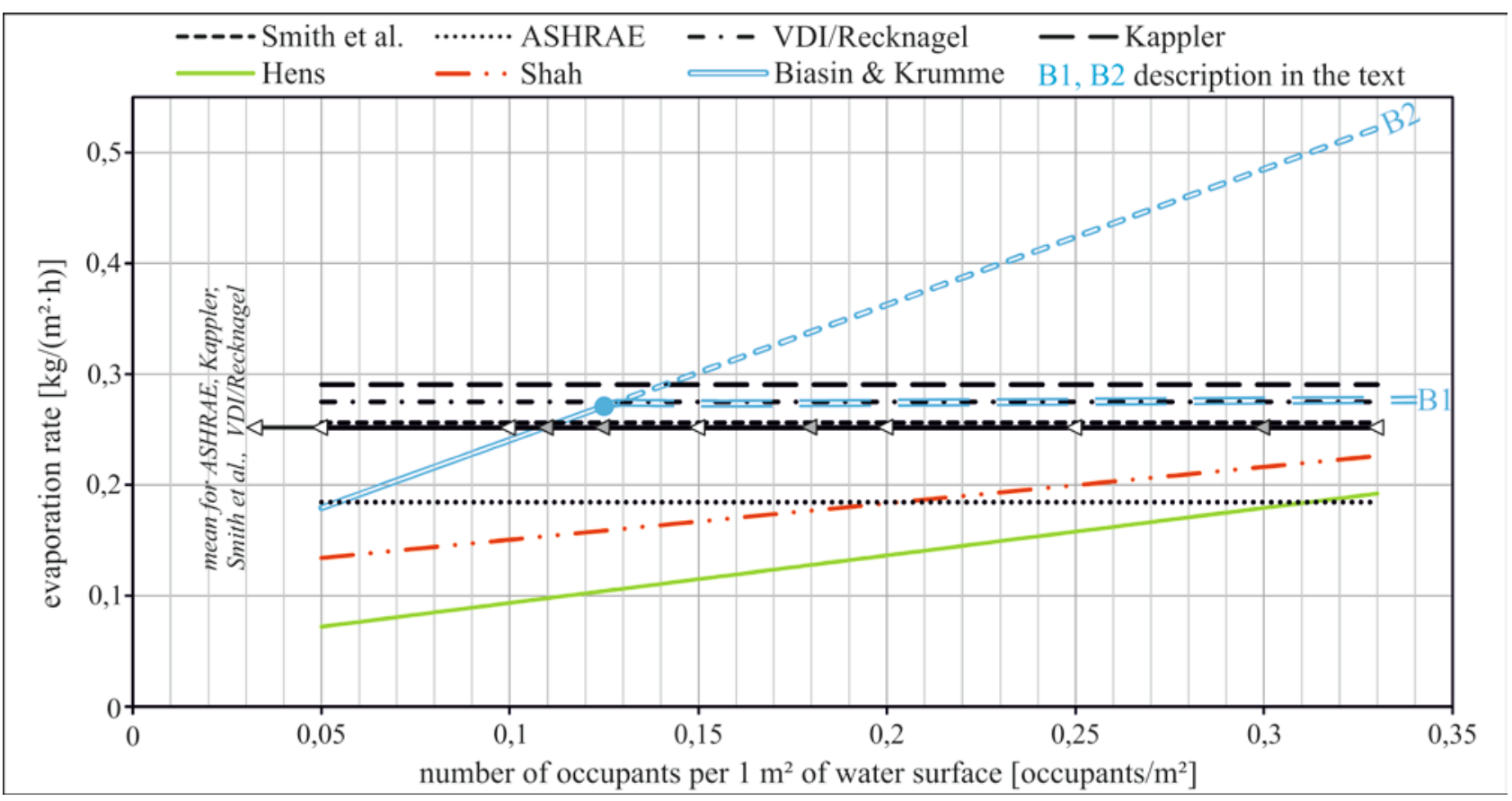

Fig. 4. Effect of the number of occupants on the evaporation rate $\left(t_{w}=27^{\circ} \mathrm{C} ; t_{a}=29^{\circ} \mathrm{C} ; \varphi=55 \% ; w=0,15 \mathrm{~m} / \mathrm{s}\right)$. 
However, when the number of occupants exceeds the value of 0,1 occupant $/ \mathrm{m}^{2}$, values of evaporation rate are very close to the mean 4 .

Values of evaporation rate calculated from equations of Shah (8) and Hens (5) rise with the rise of occupants' number. Still, these values are always lower than the mean $<$.

\section{Conclusion}

On the basis of the carried analysis, it can be stated that:

a) values of evaporation rate calculated according to relations proposed by Besler (3) and Labohm (7) differ significantly from values obtained with application of the remaining relations;

b) values of evaporation rate calculated according to relations proposed by Kappler (6), Smith et al. (9), and VDI/Recknagel (10) are close to each other and to the mean value of evaporation rate calculated only on the basis of the relations where the number of occupants is not taken into regard;

c) effect of air velocity over the water surface on moisture gains are properly described by relations proposed by Smith et al. (9) and by Kappler (6);

d) relation proposed by Biasin \& Krumme (4) considers properly the effect of occupants' number on evaporation rate; however, it should not be applied for the value of $N^{*}>0,13$ occupants $/ \mathrm{m}^{2}$;

e) values of evaporation rate calculated from relations advised by Hens (5) and Shah (8), and taking into regard the effect of number of occupants, are significantly lower than values of the parameter calculated in case when the number of occupants is not taken into regard.

\section{Symbols}

$A_{F} \quad$ coefficient in equation (3),

$A$ area of pool surface, $\mathrm{m}^{2}$,

$E$ evaporation rate from occupied pool, $\mathrm{kg} /\left(\mathrm{m}^{2} \cdot \mathrm{h}\right)$,

$E_{o} \quad$ evaporation rate from unoccupied pool, $\mathrm{kg} /\left(\mathrm{m}^{2} \cdot \mathrm{h}\right)$,

$F_{A} \quad$ activity factor in equation (2),

$K_{K} \quad$ correction factor in equation (6),

$K_{L} \quad$ correction factor in equation (7),

$N \quad$ number of pool occupants,

$N^{*} \quad$ number of occupants per pool area, $N^{*}=N / A$, occupants $/ \mathrm{m}^{2}$,

$p^{\prime}{ }_{\text {vwg }}$ vapor partial pressure in the boundary layer, Pa,

$p_{\mathrm{v} a}$ vapor partial pressure at the temperature and relative humidity of the swimming pool hall air, $\mathrm{Pa}$,

$p_{b} \quad$ atmospheric pressure, $\mathrm{Pa}$,

$t_{W B} \quad$ wet-bulb temperature, ${ }^{\circ} \mathrm{C}$,

$t_{a}$ temperature of the swimming pool hall air, ${ }^{\circ} \mathrm{C}$,

$t_{W S}$ water surface temperature, ${ }^{\circ} \mathrm{C}$,

$t_{w}$ pool water temperature, ${ }^{\circ} \mathrm{C}$,

$x^{\prime \prime}{ }_{w g}$ specific humidity of air in boundary layer, $\mathrm{kg} / \mathrm{kg}$,

$x_{a} \quad$ specific humidity of air at the temperature and relative humidity of the swimming pool hall air, $\mathrm{kg} / \mathrm{kg}$, $w \quad$ air velocity above the water surface, $\mathrm{m} / \mathrm{s}$,

$Y \quad$ latent heat of vaporization of water, $\mathrm{kJ} / \mathrm{kg}$,

$\beta_{b} \quad$ water evaporation mass transfer coefficient in equation (10), $\mathrm{m} / \mathrm{h}$,

$\Delta p \quad \Delta p=p^{\prime \prime}{ }_{\mathrm{vwg}}-p_{\mathrm{v} a}, \mathrm{~Pa}$

$\Delta x \quad \Delta x=x^{\prime \prime}{ }_{w g}-x_{a}, \mathrm{~kg} / \mathrm{kg}$,

$\varepsilon \quad$ evaporation coefficient (related to pressure), $\mathrm{kg} /\left(\mathrm{m}^{2} \cdot \mathrm{h} \cdot \mathrm{Pa}\right)$,

$\rho^{\prime \prime}{ }_{w g}$ air density in boundary layer, $\mathrm{kg} / \mathrm{m}^{3}$,

$\rho_{a} \quad$ air density in the swimming pool hall, $\mathrm{kg} / \mathrm{m}^{3}$,

$\sigma \quad$ evaporation coefficient, $\mathrm{kg} /\left(\mathrm{m}^{2} \cdot \mathrm{h}\right)$.

\section{References}

1. M. Jaskólski, Z. Micewicz, Wentylacja $i$ klimatyzacja hal krytych ptywalni (IPPU MASTA, Gdańsk, 2000)

2. H.G. Sabiniak, M. Pietras, Klimatyzacja obiektów basenowych (Wydawnictwo Politechniki Łódzkiej, Łódź, 2010)

3. A. Isańska-Ćwiek, A. Napiórkowska, Instal, 3, 46-48, (2007)

4. K. Ratajczak, E. Szczechowiak, Ciepłownictwo, Ogrzewnictwo, Wentylacja, 4, 141-148, (2010)

5. M.M. Shah, Energy and Buildings, 35(7), 707-713, (2003)

6. M.M. Shah, ASHRAE Transactions, 119(2), 450-455, (2013)

7. M.M. Shah, ASHRAE Transactions, 120(2), (2014)

8. F. Asdrubali, Energy and Buildings, 41(3), 311-319, (2009)

9. A. Napiórkowska, Ciepłownictwo, Ogrzewnictwo, Wentylacja, 5, 27-31, (2002)

10. G. Besler, Ciepłownictwo, Ogrzewnictwo, Wentylacja, 5, 142-147, (1972)

11. K. Biasin, W. Krumme, Electrowärme International, 32, 115-129, (1974)

12. H.P. Kappler, Baseny kapielowe (Arkady, Warszawa, 1977)

13. H. Recknagel, E. Sprenger, R.E. Schramek, Kompendium ogrzewnictwa $i$ klimatyzacji tacznie $z$ zagadnieniami przygotowania ciepłej wody $i$ techniki chłodniczej (OMNI SCALA, Wrocław, 2008)

14. M.M. Shah, ASHRAE Transactions, 118(2), 460-466, (2012)

15. C.C. Smith, G. Löf, R. Jones, ASHRAE Transactions, 104, 514-523, (1998)

16. K. Więcek, Ciepłownictwo, Ogrzewnictwo, Wentylacja, 3, 29-31, (2009)

17. H.G. Sabiniak, M. Pietras, Ciepłownictwo, Ogrzewnictwo, Wentylacja, 1, 28-33, (2005) 